\title{
Degradation profile of nixtamalized maize pericarp by the action of the microbial consortium PM-06
}

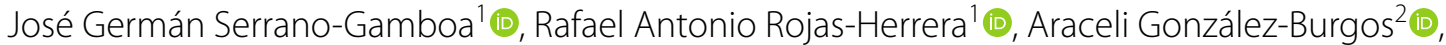

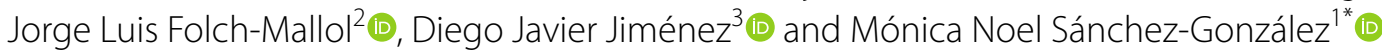

\begin{abstract}
The nixtamalized maize pericarp (NMP) is a plentiful by-product of the tortilla industry and an important source of fermentable sugars. The aim of this study was to describe the degradation profile of NMP by the action of a consortium (PM-06) obtained from the native microbial community of this residue. The degradation was analyzed in terms of the changes in the community dynamics, production of enzymes (endo-xylanase and endo-cellulase), physicochemical parameters, and substrate chemical and microstructural characteristics, to understand the mechanisms behind the process. The consortium PM-06 degraded $86.8 \pm 3.3 \%$ of NMP after $192 \mathrm{~h}$ of growth. Scanning electron microscopy images, and the composition and weight of the residual solids, showed that degradation was sequential starting with the consumption of hemicellulose. Xylanase was the highest enzyme activity produced, with a maximum value of $12.45 \pm 0.03 \mathrm{U} \mathrm{mL}^{-1}$. There were fluctuations in the $\mathrm{pH}$ during the NMP degradation, starting with the acidification of the culture media and finishing with a pH close to 8.5. The most abundant species in the consortium, at the moment of maximum degradation activity, were Aneurinibacillus migulanus, Paenibacillus macerans, Bacillus coagulans, Microbacterium sp. LCT-H2, and Bacillus thuringiensis. The diversity of PM-06 provided metabolic abilities that in combination helped to produce an efficient process. The consortium PM-06 generated a set of different tools that worked coordinated to increase the substrate availability through the solubilization of components and elimination of structural diffusion barriers. This is the first report about the degradation of NMP using a microbial consortium.
\end{abstract}

Keywords: Nixtamalized maize pericarp, Endogenous microbial consortium, Lignocellulose degradation mechanism, Xylanase and cellulase activities

\section{Introduction}

Agro-industrial residues are important sources of fermentable sugars useful for the production of biofuels, biomaterials and biocatalysts (Bhatia et al. 2012). However, the structural complexity makes the sustainable use of these residues a technological challenge. In Mexico and Central America, maize is nixtamalized before consumption (Serna-Saldivar 2016). This

\footnotetext{
*Correspondence: monica.sanchez@correo.uady.mx

${ }^{1}$ Facultad de Ingeniería Química, Universidad Autónoma de Yucatán, Campus Ciencias Exactas e Ingenierías, Periférico Norte, Kilómetro 33.5, Tablaje Catastral 13615, Chuburná de Hidalgo Inn, Mérida, Yucatán, Mexico

Full list of author information is available at the end of the article
}

process, involves the alkaline cooking and steeping of maize grains in a lime solution. Nixtamalized maize is used for the production of different staples within the Mexican diet, such as "tortillas". Millions of tons of maize are processed annually, generating significant amounts of by-products including nixtamalized maize pericarp (NMP) (Campechano-Carrera et al. 2012; García-Zamora et al. 2015). Nixtamalization modifies the external layers of pericarp and promotes the partial solubilization of hemicellulose, without affecting the structure of the internal tissue (Gutiérrez-Cortez et al. 2010). The integrity of pericarp after nixtamalization, depends on the processing conditions (time and temperature of cooking and alkali concentration) 
(Gutiérrez-Cortez et al. 2010). Industrial NMP is a residue rich in hemicellulose $(\sim 45 \%)$, followed by cellulose $(\sim 19 \%)$, starch $(\sim 13 \%)$ and lignin $(\sim 5 \%)$ (Rostro-Alanís et al. 2014). Like other recalcitrant lignocellulosic structures, NMP requires the use thermochemical $\left(207{ }^{\circ} \mathrm{C}\right)$ or harsh alkaline treatments to recover high valuable components such as hemicellulose (López-Martínez et al. 2011; Rostro-Alanís et al. 2014).

In nature, microbial communities decompose plant polysaccharides by the synergistic action of thousands of species (Jose et al. 2017; Tláskal et al. 2017). The selection of lignocellulolytic microbial consortia has been considered a promising approach to improve the saccharification of agricultural residues (Carlos et al. 2018; Cortes-Tolalpa et al. 2016; Du et al. 2015). In consortia, microorganisms co-exist, secrete an array of enzymes, and act in synergic ways to efficiently release sugars from plant polysaccharides. Moreover, the culture conditions, microbial origin, type of substrate and the dynamic of conditions present in the system, are main drivers of the diversity and metabolic potential in a lignocellulose degrading consortium (Jiménez et al. 2017; Zhu et al. 2016). Therefore, lignocellulose degradation by consortia is multifactorial and must be analyzed in a holistic way to understand the mechanisms involved.

The high content of organic matter present in the nixtamalization residues, suggests the abundant presence of microorganisms (Sanchez-Gonzalez et al. 2011). However, the microbiota of these residues and their potential uses have not been fully explored. Paenibacillus amyloliticus, Pseudomonas putida and Acinetobacter were isolated from soil contaminated with nixtamalization liquors (nejayote) (SalmeronAlcocer et al. 2003). These microorganisms are known as degraders of lignocellulose components or members of lignocellulose degrading consortia (Auer et al. 2017; Keggi and Doran-Peterson 2019; Ravi et al. 2017). Moreover, strains of Bacillus flexus isolated from nejayote were able to release phenolic acids from NMP (Sanchez-Gonzalez et al. 2011). These evidences suggest the potential ability of the microorganisms present in the nixtamalization residues to degrade lignocellulose. In this work is described the degradation profile of NMP by the action of the consortium PM-06, obtained from the native microbial community of this residue. The degradation was analyzed in terms of the changes in the community dynamics, production of enzymes (endo-xylanase and endo-cellulase), physicochemical parameters, and substrate chemical and microstructural characteristics, to understand the mechanisms behind the process.

\section{Materials and methods}

Origin and selection of the native microbial consortium PM-06

Consortium PM-06 was enriched from the endogenous microbiota in NMP by the dilution-to-stimulation approach (Lee et al. 2013). Cell suspensions of the NMP microbiota were obtained according to De Lima Brossi et al. (2016). Aliquots of $250 \mu \mathrm{L}$ of this cell suspension were added to $25 \mathrm{~mL}$ of a medium containing $40 \mathrm{~g}$ NMP L $L^{-1}$ (Harinera de Yucatán, S.A. de C.V., Mérida, México) and 5 g yeast extract $\mathrm{L}^{-1}$, and incubated at $37^{\circ} \mathrm{C}$ and $125 \mathrm{rpm}$ for 7 days. After the incubation time, $2 \mathrm{~mL}$ of these cultures were used to inoculate fresh media. This procedure was repeated until the functional stability was maintained. The functional stability was determined measuring the amount of residual NMP present in the culture after $168 \mathrm{~h}$. All experiments were conducted in triplicate. The composition of the NMP lot used was: $15.3 \%$ cellulose, $23.7 \%$ xylan, $12.6 \%$ arabinose substituents, $33 \%$ starch, $4.4 \%$ lignin, and $11 \%$ of others components (ashes, extractives, uronic acids and protein).

\section{Consortium PM-06 culture conditions for the degradation of NMP}

The microbial consortium PM-06 was cultivated in $25 \mathrm{~mL}$ of media containing $40 \mathrm{~g}$ dried $\mathrm{NMP} \mathrm{L^{-1 }}$ and $5 \mathrm{~g}$ yeast extract $\mathrm{L}^{-1}$. These flasks were inoculated with $2 \mathrm{~mL}$ of the stable consortium and incubated at $37{ }^{\circ} \mathrm{C}$ and $125 \mathrm{rpm}$ for $192 \mathrm{~h}$. Samples were taken at regular time intervals $(0,4,8,12,24,48,72,96,120,144,168$, $192,216,240$, and $288 \mathrm{~h}$ ) to measure the weight of the residual NMP, cell protein content, enzymatic activities, pH (Thermo Orion 0420A1 pH meter), and the concentration of reducing and total sugars in the culture broth. Negative controls consisted of culture media without inoculum. All experiments were conducted in triplicate.

\section{Evaluation of the degradation rates of NMP}

Cultures were harvested by filtration through filter paper $(11 \mu \mathrm{m}$ pore size) under vacuum. Retained solids were dried at $60{ }^{\circ} \mathrm{C}$ in a convection oven for $24 \mathrm{~h}$ after which the weight of the residual NMP was measured. The NMP degradation (\%) was calculated with the following formula:

$$
[(W t-W i) / W t] \times 100 ;
$$

where $W t$ is total NMP weight before microbial growth; and $W i$ is the residual substrate weight after microbial growth. The degradation rates were calculated dividing the NMP degradation percentage by the time (h after inoculation). 


\section{Determination of the microbial growth}

The microbial growth was quantified by measuring the total cellular protein concentration. Culture filtrates $(1 \mathrm{~mL})$ were centrifuged at $11,000 \times g$ and $4{ }^{\circ} \mathrm{C}$ for $5 \mathrm{~min}$. The resulting cell pellets were disrupted by incubation with $1 \mathrm{~mL}$ of $\mathrm{NaOH} 500 \mathrm{mM}$, at $75^{\circ} \mathrm{C}$ for $10 \mathrm{~min}$. Cellular lysates were centrifuged at $16,000 \times g$ and $10^{\circ} \mathrm{C}$ for $10 \mathrm{~min}$, and then the supernatant was collected. Cellular lysate protein concentrations were determined using a modified version of the Lowry protein assay (Peterson 1977) using BSA curve ( 5 to $50 \mu \mathrm{g}$ ) as protein standard.

\section{Quantification of soluble sugars}

During microbial growth, the concentration of reducing sugars in the supernatant was measured using the 3,5-dinitrosalicylic acid (DNS) method (Miller 1959), while the total sugars concentration was determined by the phenol-sulfuric colorimetric assay (DuBois et al. 1956).

\section{Determination of endo-xylanase and endo-cellulase activities in the culture supernatants}

The activities of these hydrolytic enzymes were evaluated in the culture supernatants measuring the amount of reducing sugars released upon substrate hydrolysis by the DNS method. The endo-xylanase activity was assayed at $\mathrm{pH} 6.5$ and $60^{\circ} \mathrm{C}$ for $15 \mathrm{~min}$ in reactions containing $1.8 \%(\mathrm{wt} / \mathrm{v})$ xylan from beechwood (Sigma) in phosphate buffer $100 \mathrm{mM}$. The endo-cellulase activity was measured at $\mathrm{pH} 4$ and $40{ }^{\circ} \mathrm{C}$ for $15 \mathrm{~min}$ in reactions containing $0.5 \%(\mathrm{wt} / \mathrm{v})$ carboxymethylcellulose (CMC) (Sigma) in citrate buffer $500 \mathrm{mM}$. One unit of endo-xylanase or endo-cellulase activity was defined as the amount of enzyme that catalyzed the production of $1 \mu \mathrm{mol}$ of reducing sugars (xylose or glucose) per minute under the described conditions.

\section{Compositional analysis of residual NMP after PM-06 growth}

Structural carbohydrates and Klason lignin content in the residual NMP were measured by quantitative acid hydrolysis using sulfuric acid (TAPPI T13M method). The monosaccharides obtained from the residual NMP, were quantified by high performance liquid chromatography with refractive index detection (1220 Infinity II LC Systems, Agilent Technologies, US). Separations were carried out over a Phenomenex RPM-Monosaccharide column $(00 \mathrm{H}-0135-\mathrm{K} 0)$ at $80{ }^{\circ} \mathrm{C}$, using water as

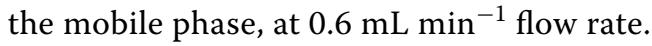

\section{Scanning electron microscopy (SEM)}

The supramolecular morphology of residual NMP particles was determined using a scanning electron microscope (Jeol JSM-6360 LV). For this purpose, samples were coated with gold using a Denton Vacuum Desk II sample metallizer. The images were acquired at $20 \mathrm{kV}$ accelerating voltage.

\section{Analysis of the bacterial dynamics using denaturing gradient gel electrophoresis (DGGE)}

For the analysis of the bacterial dynamics using DGGE, the metagenomic DNA (mgDNA) of the degradation kinetics was extracted. Cultures were filtered through filter paper to eliminate the residual NMP. Cells were recovered after centrifugation of filtrates, at $11,000 \times g$ for $10 \mathrm{~min}$ at room temperature. The cell pellets obtained were washed (twice) with TEN buffer $(100 \mathrm{mM}$ Tris- $\mathrm{HCl}$, $50 \mathrm{mM}$ EDTA, $100 \mathrm{mM} \mathrm{NaCl}, \mathrm{pH}$ 8), to eliminate culture medium residues. The mgDNA was extracted using the methodology reported by Rojas-Herrera et al. (2008). The isolated mgDNA, was utilized as a template to amplify the $\mathrm{V} 3$ region of the bacterial 16S rRNA gene through PCR using the previously reported primers GC338f and 518r (Muyzer et al. 1993). Conventional PCR with GoTaq Flexi DNA polymerase (Promega) was performed using 50 ng of mgDNA. PCR conditions included a $94{ }^{\circ} \mathrm{C}$ denaturation for $5 \mathrm{~min}$, followed by 40 cycles of $94{ }^{\circ} \mathrm{C}$ for $1 \mathrm{~min}, 60{ }^{\circ} \mathrm{C}$ for $1 \mathrm{~min}$, and $72{ }^{\circ} \mathrm{C}$ for $1 \mathrm{~min}$. The process concluded with an elongation stage of $72{ }^{\circ} \mathrm{C}$ for $10 \mathrm{~min}$. Amplicons were analyzed by DGGE using the DCODE Universal Mutation Detection System (BioRad Laboratories). PCR products were loaded into a $6 \%$ polyacrylamide gel with a denaturing gradient urea:formamide of 30 to $70 \%$. Electrophoresis conditions were $70 \mathrm{~V}$ for $16 \mathrm{~h}$ at $60{ }^{\circ} \mathrm{C}$ in $1 \times$ tris-acetate-EDTA (TAE) buffer. The gel was stained with SYBR Gold dye (Molecular Probes) and viewed with a Gel Doc XR system photo documentary device (BioRad). Bacterial structure dynamics during degradation was determined using a similarity analysis based on the Jaccard index, followed by unweighted pair-group method analysis (UPGMA) to construct a clustered dendrogram with the BioNumerics software (Applied Maths). Species richness were calculated with the SDR ver. 1.4.2 software (Pisces Conservation LTD) using densitometry data and identified DGGE band counts as input data.

\section{mgDNA sequencing and data processing}

The sequencing of the extracted mgDNA ( $8 \mathrm{~h}$ samples), was carried out at Admera Health Inc. (NJ, USA), using the Illumina NextSeq platform. Output files were processed by Trimmomatic (Bolger et al. 2014) and checked 
by FastQC suite. Sequencing data, with a Phred quality score $\geq 25$, were assembled using the IDBA_UD algorithm (Peng et al. 2012), and aligned with DIAMOND (Buchfink et al. 2014) against the NCBI nr database (e-value threshold of $1 \mathrm{e}^{-5}$ ) for taxonomic classification.

\section{Results}

Microbial growth, $\mathrm{pH}$ and NMP degradation profiles

The consortium PM-06 was obtained after the enrichment and stabilization of the native microbiota present in NMP. The evolution of the microbial growth and $\mathrm{pH}$ were analyzed during the degradation of NMP by PM-06 (Fig. 1a). Microbial growth profile showed the absence of a lag phase as consequence of the successive cultivation. Moreover, as result of the microbial metabolism, $\mathrm{pH}$ fluctuated along the culture.

The degradation profile of NMP was divided into three stages according to the calculated degradation rates (Fig. 1b). From 0 to $8 \mathrm{~h}$ (stage I), the maximum degradation rate occurred $(4.95 \pm 0.96 \%$ of NMP degraded per hour) resulting in around $40 \%$ of total consumption. From 8 to $72 \mathrm{~h}$ (stage II), the degradation rates decreased and the total percentage of NMP degraded reached 56\%. From 72 to 192 h (stage III), the lowest degradation rates were obtained and the maximum percentage of NMP degraded (86.8\%) was reached at $192 \mathrm{~h}$. No further changes were observed after this time.

Results indicate the existence of a relationship between the microbial growth, $\mathrm{pH}$ and NMP degradation. The stage I is coincident with the early exponential phase of growth and the acidification of the culture medium. During the stage II, the exponential phase ends and the $\mathrm{pH}$ started increasing. Finally, in the stage III the protein cell concentration declined and the maximum $\mathrm{pH}$ values (close to 8.5) were obtained. It is important to note that culture media contains yeast extract and starch derived from the nixtamalization process; however, results indicate that the consumption of NMP was the main metabolic activity.

\section{Sugar concentration in the culture supernatant}

The solubilization of NMP into the medium was determined through the quantification of the total and reducing sugars (Fig. 2a). Total sugars concentrations were one order of magnitude higher than the reducing ones, suggesting the abundance of molecules with high degree of polymerization (DP). During the first $4 \mathrm{~h}$, the concentration of both parameters increased; however, the reducing sugars decreased after this time possibly because include molecules with low DP (mono and oligosaccharides) which can be directly transported into the cytoplasm for further metabolic processing. The stage II was characterized by a decrement in the solubilized sugars, whilst in the stage III a slight increment was observed.

\section{Production of endo-xylanase and endo-cellulase enzymatic activities}

The consortium PM-06 is a prolific endo-xylanase producer, the activities measured were within the interval reported for consortia with high xylanase titles (Zhang et al. 2018), and were one order of magnitude greater than endo-cellulases. Results indicate the presence of differences in the production profile and fluctuations of the activities over time. During the stage I of degradation, both enzymatic activities increased obtaining the maximum value for endo-cellulases at the end of this period (Fig. 2b) The highest endo-xylanase activity was attained in the stage III, at $144 \mathrm{~h}$ of growth. Interestingly, a similar behaviour in the production of both activities was observed in the degradation stage III. The fluctuations observed, could be the result of changes in gene expression, proteolysis, and microbial successional events (Bohacz 2018; Jiménez et al. 2018; Li et al. 2017).

\section{Composition and surface structural analysis of NMP}

Changes in the composition and surface structure of residual NMP were analyzed during the degradation process. The relative composition in terms of cellulose; hemicellulose (xylan and arabinose substituents); and lignin, was determined and presented in Fig. 3a. Results indicate that NMP was sequentially degraded, beginning with the components of the hemicellulosic fraction (Fig. 3a). The highest degradation rates of hemicellulose were observed during stage I; however, at $4 \mathrm{~h}$ the arabinose substituents degradation rate was almost twice the xylan rate. The content of arabinose and xylan in NMP decreased around 50\% at the end of this lapse of time (Fig. 3b). Cellulose degradation occurred at lower rates, obtaining the highest values also during the stage I (Fig. 3b). The cellulose solubilized in the stage I corresponded to $35 \%$ of the total degraded (Fig. 3a). The lignin content along the degradation process showed an erratic behaviour, reaching a degradation around 50\% after $48 \mathrm{~h}$ of incubation.

Structurally, NMP consists of three zones with a different morphology: zone I is associated with the pedicel; zone II with the embryo; and the zone III covers the endosperm (Gutiérrez-Cortez et al. 2010). This study was focused on the microstructural changes in the surface of the zone III that accounts for the $90 \%$ of the intact NMP.

SEM images showed the presence of starch granules, and cellulose and hemicellulose fibers in the surface of NMP prior sterilization (Fig. 3c). The structural characteristics are coincident with the described by Gutiérrez-Cortez et al. (2016), where the integrity of cellulose 

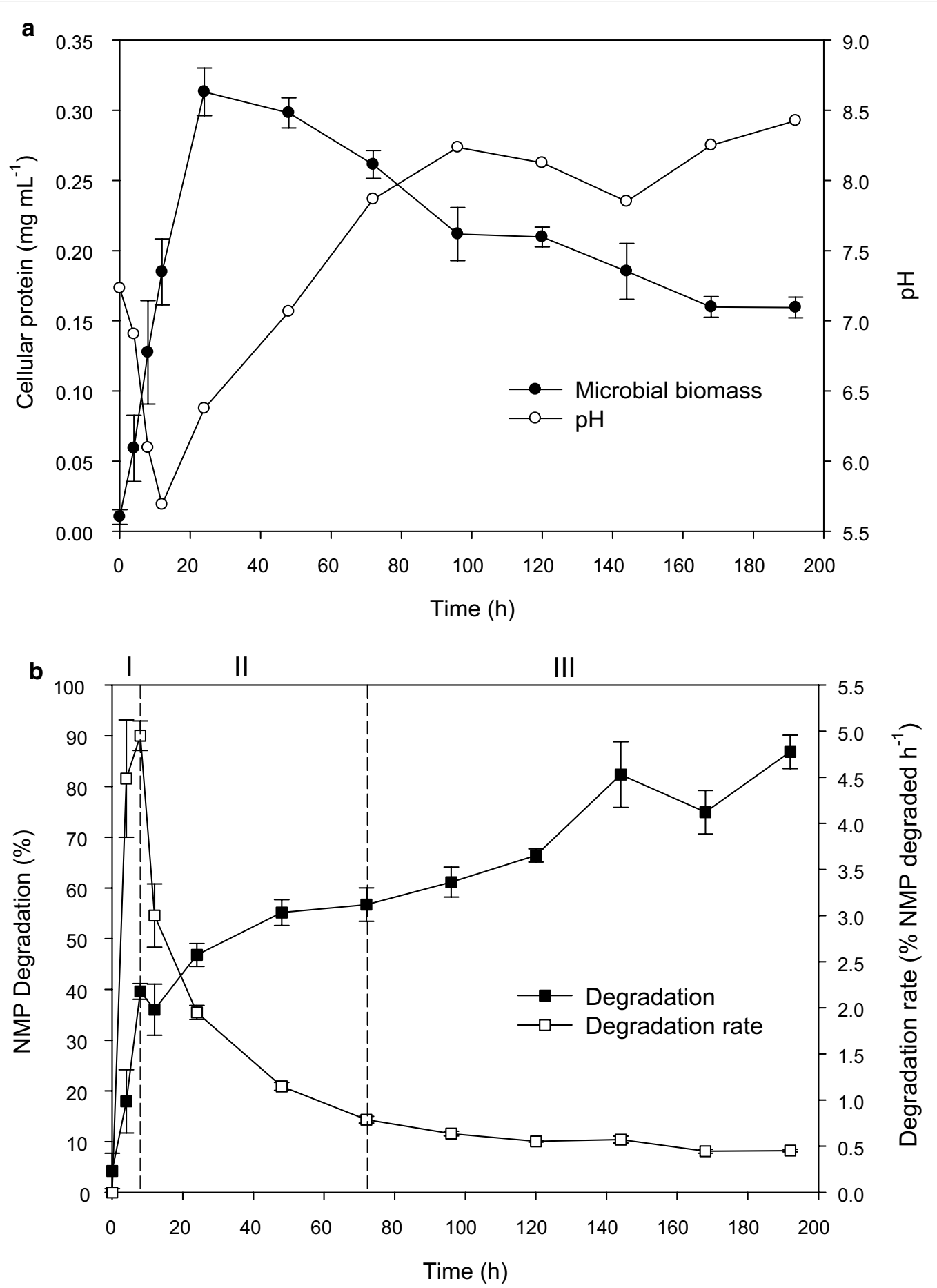

Fig. 1 NMP solids consumption, cellular protein concentration and pH profiles. PM-06 growth in terms of cellular protein concentration and pH dynamics (a). NMP consumption in terms of the percentage of weight loss and degradation rates $(\mathbf{b})$. The NMP degradation stages are indicated with the roman numerals I, II and III on the top of the panel

and hemicellulose structure was maintained after nixtamalization. Sterilization solubilized the starch granules but maintained intact the plant cell wall structure
(Additional file 1: Figure S1). After $12 \mathrm{~h}$ (stage II), the NMP surface was less structured with the fibers of cellulose more exposed. At $72 \mathrm{~h}$, the plant cell wall structure 

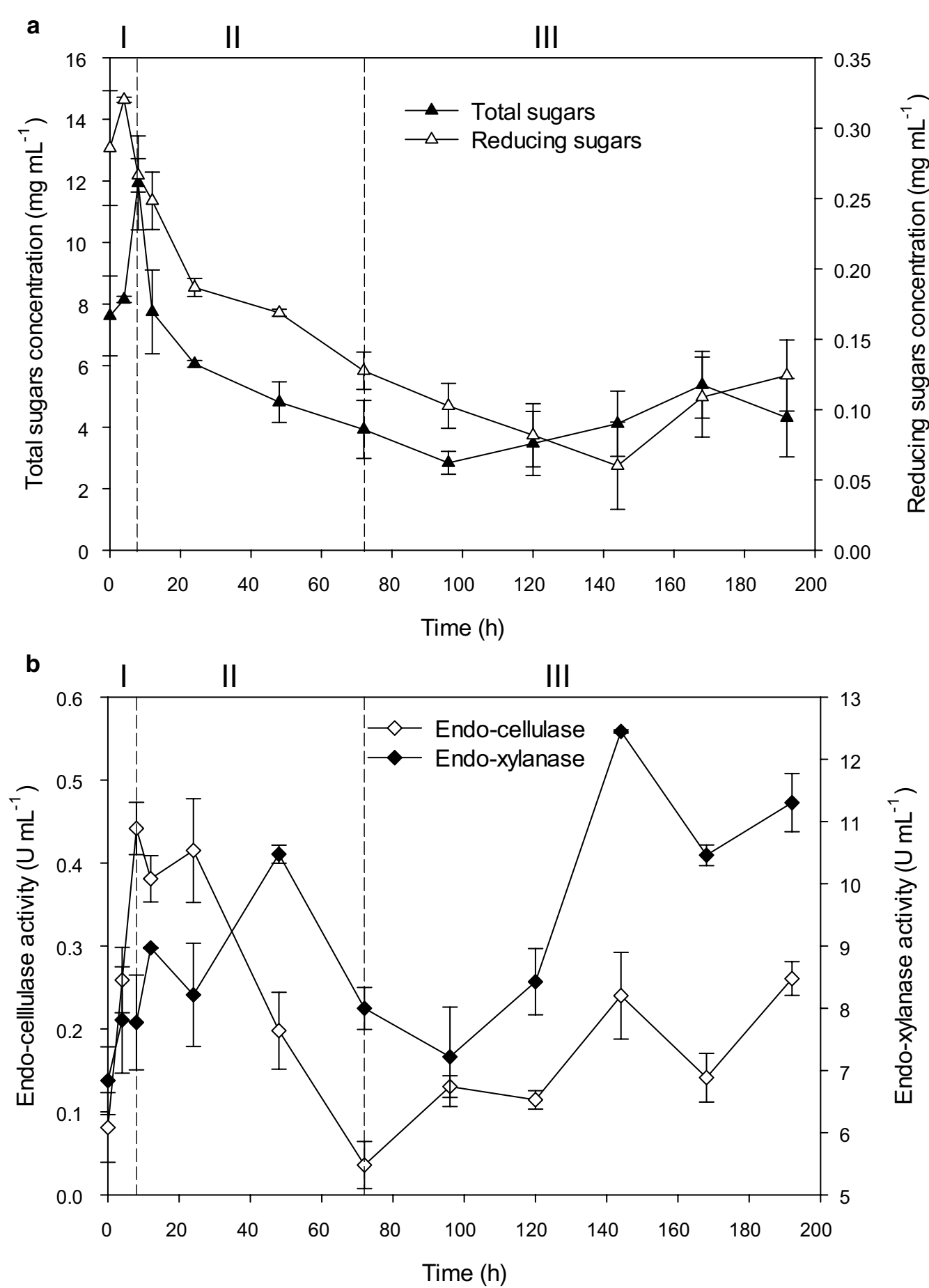

Fig. 2 Concentration of soluble sugars and production of enzymatic activities along the degradation of NMP. Total and reducing sugars concentration (a). Endo-xylanase and endo-cellulase activities (b)

was loosened with cavities that exposed internal portions of the tissue (Fig. 3c). At the end of the process, the NMP deterioration was deep with fissures, pores and trenches across large areas. The internal tissue was completely exposed allowing the diffusion of enzymes and bacterial cells (Fig. 3c). 


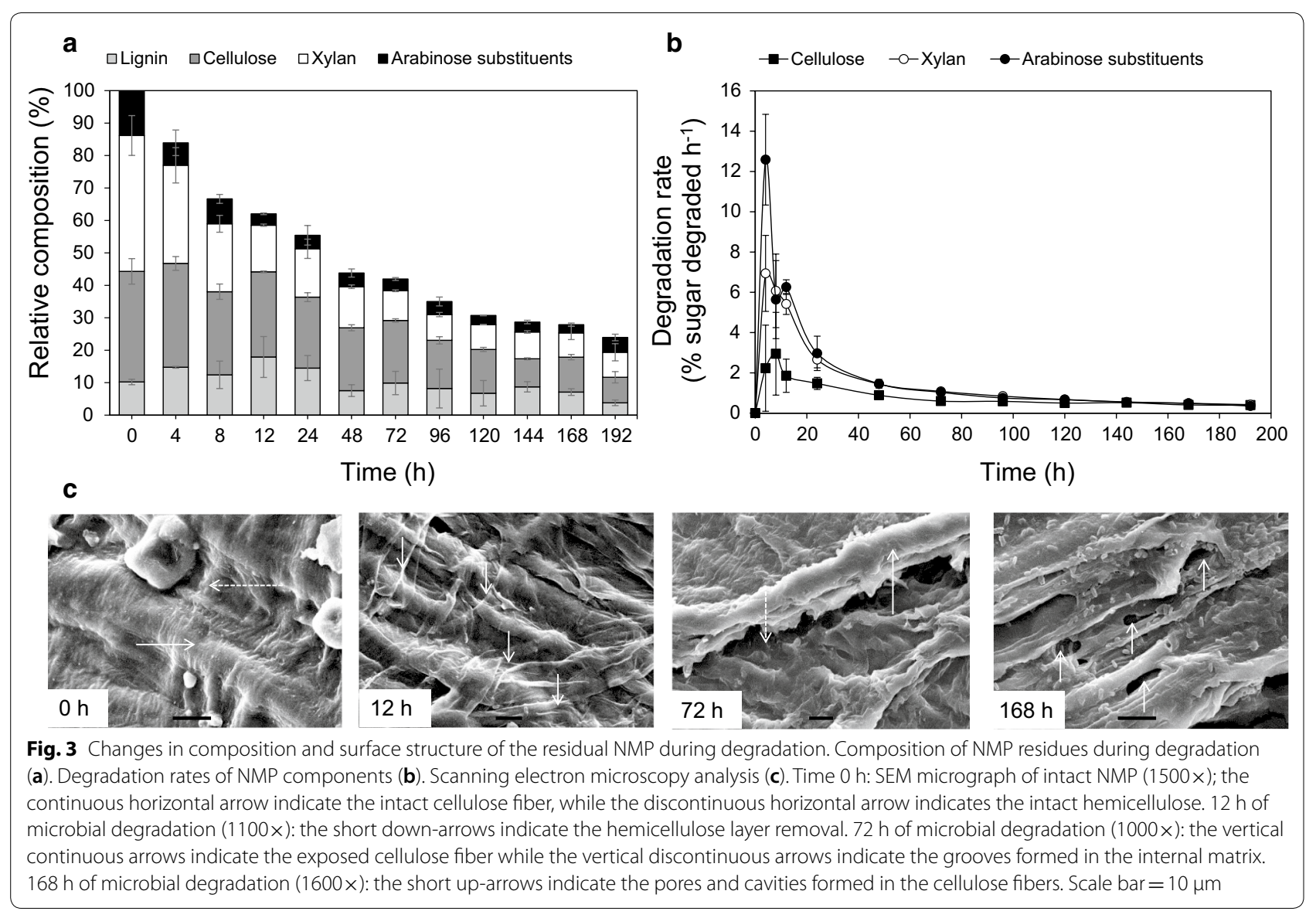

\section{Microbial community dynamics and taxonomy}

The DGGE fingerprints of PM-06 during the NMP degradation, showed variations in the number of operational taxonomic units (OTUs) along the batch of culture (Fig. 4a, Table 1). The number of OTUs (richness) increased during stage I reaching a maximum number at $8 \mathrm{~h}$. In the stage II, the richness started decreasing obtaining the minimum value at $48 \mathrm{~h}$. After this time, the richness became almost constant. The UPGMA dendrogram constructed from DGGE band patterns, showed that samples clustered in two different clades with approximately $50 \%$ of similarity (Fig. $4 \mathrm{~b}$ ). Notably, the lanes corresponding to the initial degradation times clustered with the final ones, suggesting a cyclical behaviour.

Samples representing the time with the highest degradative activity and OTUs richness $(8 \mathrm{~h})$, were analyzed by metagenomics. The assembled metagenome statistics are detailed in Additional file 1: Table S1. A total of 24,879 sequences were taxonomically classified. Taxonomic analysis showed the predominance of the Bacteria domain $(99.94 \%)$ and within this, the phyla Firmicutes (76.31\%) and Actinobacteria (13.66\%) were the most abundant. Moreover, 156 bacterial genera were identified (sequence identity $\geq 97 \%$ ), but only seven presented relative abundances above $1 \%$. The top five species identified in PM-06 were Aneurinibacillus migulanus (29\%), Paenibacillus macerans (26\%), Bacillus coagulans (15.6\%), Microbacterium sp. LCT-H2 (11\%), and Bacillus thuringiensis (4.7\%).

\section{Discussion}

Nixtamalization is an ancient procedure created by early Mesoamerican cultures for the transformation of maize into products with high nutritional content and more palatability (Serna-Saldivar 2016). In the global era, nixtamalized products (tortillas, chips, etc.) became popular around the world and have been even frequently included in the diet of astronauts (Serna-Saldivar 2016). Predictions indicate a substantial growth of the nixtamalization industries in the coming years (Future Market Insights 2018). NMP is an abundant residue from the nixtamalization industry, and an important source of fermentable sugars. However, few efforts have been made to harness NMP for the production of commodity chemicals. Arabinoxylooligosaccharides with potential prebiotic and antioxidant activities, as well as gums, have been obtained 


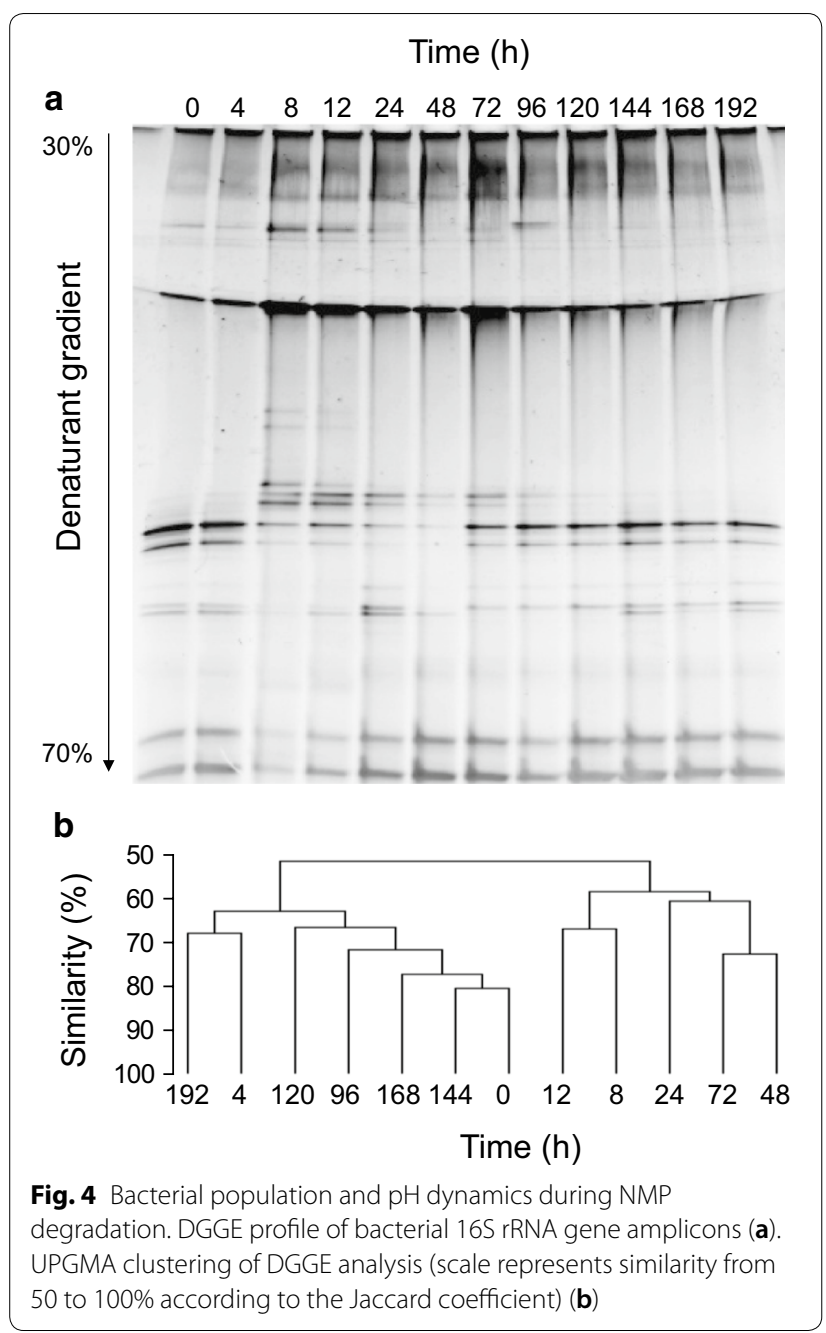

Table 1 Diversity analysis obtained from DGGE pattern related to richness and Shannon index

\begin{tabular}{lll}
\hline Sampling times $(\mathbf{h})$ & Richness (n OTUs) & $\begin{array}{l}\text { Shannon } \\
\text { index }(\mathbf{H})\end{array}$ \\
\hline 0 & 11 & 2.041 \\
4 & 14 & 2.31 \\
8 & 19 & 2.7 \\
12 & 15 & 2.502 \\
24 & 14 & 2.405 \\
48 & 10 & 1.956 \\
72 & 13 & 2.317 \\
96 & 13 & 2.23 \\
120 & 12 & 2.185 \\
144 & 13 & 2.231 \\
168 & 12 & 2.168 \\
192 & 12 & 2.269 \\
\hline
\end{tabular}

from the hemicellulosic fraction of NMP, using chemical and physicochemical procedures (Carvajal-Millan et al. 2007; Rostro-Alanís et al. 2014). Attempts to use biological methods are scarce, mainly because usually involve pretreatments followed by the application of enzyme preparations (Rostro-Alanís et al. 2014). The employment of a single biological strategy to overcome the recalcitrance of different lignocellulose matrices is not always efficient because the organization and composition of the main biopolymers (cellulose, hemicellulose and lignin), depend on the species, tissue, and maturity of the plant cell wall (Ciolacu 2018). Moreover, the characteristics of industrial residues depend on the process conditions. In nature, microbial communities accomplish the degradation of a variety of lignocellulosic tissues using degradation strategies that result from the metabolic capabilities of the microbial members, the establishment of ecological interactions, and the structure and composition of the substrate (Cortes-Tolalpa et al. 2016; Carlos et al. 2018). Therefore, understanding the mechanisms used by microbial communities for the degradation of lignocellulose, is crucial for the optimization of processes and the design and production of tailored commercial enzymatic preparations.

NMP degradation, apparently corresponds to an endogenous heterotrophic succession where the abundance of the PM-06 members fluctuates as result of changes in substrate structure, availability of easy metabolizable substrates, microbial interactions, physicochemical conditions of the media, and metabolic versatility of key microorganisms (Fierer et al. 2010; Jiménez et al. 2017). The degradation was sequential with fluctuations in the $\mathrm{pH}$ of the media along the process. Stage I was characterized by a fast decrement of NMP solids and $\mathrm{pH}$. The presence of high degradative activities in early stages of culture has been related with the exponential phase, where microorganisms grow rapidly, achieving a fast degradation of lignocellulose (Liang et al. 2017; Zhang et al. 2018). Moreover, literature reports high expression levels of lignocellulolytic enzymes during the first hours of growth (Alessi et al. 2018; Jiménez et al. 2018). Fluctuations in the $\mathrm{pH}$ of media along the degradation process is frequently reported in lignocellulose-degrading microbial consortia (Alessi et al. 2018; Hui et al. 2013; Liang et al. 2017; Wongwilaiwalin et al. 2010; Zhang et al. 2018). The acidification has been identified as a consequence of fermentative processes in which microorganisms produce organic acids. Thus, during the exponential phase the PM-06 members acquire energy mainly through the fermentation of sugars obtained from NMP degradation. In this stage, only $35 \%$ of cellulose was degraded, a fraction which probably corresponds to the amorphous structural regions. The main sugars released from NMP were 
arabinose and xylose; however, in the first $4 \mathrm{~h}$ of culture, arabinose substituents elimination rate was higher than xylan degradation. In NMP, the xylan backbone of hemicellulose is highly substituted with arabinose and other molecules (Rostro-Alanís et al. 2014) that block the action of endo-xylanases (Agger et al. 2010; Correia et al. 2011). The early enzymatic elimination of arabinose units is a synergistic strategy to facilitate the action of endoxylanases, promoting the xylan hydrolysis (Agger et al. 2010; Correia et al. 2011; Biely et al. 2016). During the degradation of NMP solids, high DP soluble sugars are released into the medium. These sugars are further saccharified for the production of molecules easily metabolized by microorganisms.

In stage I, the endo-cellulases peaked and $70 \%$ of the maximum endo-xylanase activity was present. It is well known the existence of a synergistic relationship between cellulases and xylanases (Hu et al. 2011; Kim et al. 2014; Malgas et al. 2017), that could be favoured by the $\mathrm{pH}$ conditions. Although xylanases from Bacillus and Paenibacillus have demonstrated to be active on a broad $\mathrm{pH}$ range (5 to 12) (Mongkorntanyatip et al. 2017; Kurrataa'Yun and Meryandini 2015), the optimal pH interval for the majority of the bacterial endoglucanases is from 5 to 7 (Orencio-Trejo et al. 2016; Sadhu and Maiti 2013). Under these physicochemical conditions, the removal of xylan by endo-xylanases, would allow the access of endo-cellulases to degrade cellulose microfibrils. On the other hand, the degradation of cellulose would allow the access of xylanases to deeper structures. In addition to endo-cellulases and endo-xylanases, other enzymes not measured in this work, like lytic polysaccharide monooxygenase (LPMO), and ligninases, could also enhance the lignocellulose degradation (Bissaro et al. 2018; Hu et al. 2018). The synergistic relationship between enzymes maximize the degradation of cellulose even with low endo-cellulase activity titles. SEM micrographs evidenced the exposition of cellulose fibres after the elimination of hemicellulose from the surface of the residue and the formation of cavities, in further times, that provide access not only to enzymes but also to microorganisms. The degradation process is focused in the elimination of the diffusion barriers for the permeation of water and enzymes.

The degradation of NMP in stage I was faster than the reported for other consortia using different residues ( $8 \mathrm{~h}$ compared to 3 to 6 days), likely as consequence of the NMP structure (Zhang et al. 2018; Liang et al. 2017). Nixtamalization originates changes in the external layers of pericarp such as the loss of cuticle, and formation of pores (Gutierrez et al. 2007; Gutiérrez-Cortez et al. $2010,2016)$ that may increase the substrate availability and accessibility of water and enzymes, promoting a fast degradation.
NMP components were consumed at lower rates in stages II and III. Interestingly, in these periods of time the $\mathrm{pH}$ of the media was alkalinized. Alkalinization has been related to different metabolic events like organic acids consumption, and the secretion and accumulation of aminoacid catabolic products, between others (Pometto and Crawford 1986; Alessi et al. 2018). In PM-06 cultures, the $\mathrm{pH}$ of the medium increased as soon as the concentration of soluble sugars decreased. Some bacteria, like the lactic acid bacteria, response to starvation conditions through the alkalinization of the cytosolic and extracellular pH (Papadimitriou et al. 2016). Alkaline conditions increase the solubility of lignin and cellulose (Pometto and Crawford 1986; Evstigneev 2011), favouring the enzymatic attack. Moreover, alkalinization promoted modifications in the PM-06 bacterial succession inducing probably the growth of microorganism able to produce alkaliphilic enzymes or to degrade aromatic compounds like those present in lignin (Alessi et al. 2018; Carlos et al. 2018).

There is an apparent relationship between the diversity and the capacity of a consortium to degrade lignocellulose (Evans et al. 2017; Jiménez et al. 2017). Therefore, consortia are usually obtained from the enrichment of extremely diverse communities like the present in compost or soil. In contrast, PM-06 microbiome is the product of two selection processes, the first was nixtamalization and the second was the enrichment of the NMP microbiome to obtain the stabilized consortium. However, in this case an efficient lignocellulose-degrader consortium was obtained from of a selected source of microorganisms. As result of the selection conditions, the composition of PM-06 widely differs from the selected native microbiota present in unprocessed maize pericarp natural fermentations, where yeasts and bacteria from the Lactobacillales order were abundant (Decimo et al. 2017). The effect of diversity on the effectiveness of degradation was observed during the process. At $8 \mathrm{~h}$, the maximum values of degradation and microbial diversity and richness were obtained. The increment in diversity provided different and redundant metabolic abilities that in combination produced an efficient process.

Microorganisms present in PM-06 are part of the Bacteria domain and members of the Bacillales and Actinomycetales orders. The most abundant genera were Bacillus, Aneurinibacillus, Paenibacillus, and Microbacterium. Several species of Bacillus and Paenibacillus are recognized as great plant biomass degraders (Ghio et al. 2018; Orencio-Trejo et al. 2016). These microorganisms synthesize lignocellulolytic enzymes active under different $\mathrm{pH}$ and temperature conditions (Gao et al. 2018; Gastelum-Arellanez et al. 2014; Zhang et al. 2017). The genus Aneurinibacillus is part of the ruminal microbiota 
able to synthesize enzymes that work on lignocellulose (Asem et al. 2017). In contrast, Microbacterium species contain few genes encoding for lignocellulolytic enzymes; however, possess a great metabolic potential to degrade arabinoxylans (Yeager et al. 2017). Bacillales and Actinomycetales are frequently present in plant biomass-degrading consortia and different studies suggest a synergistic relationship between them (Azizi-Shotorkhoft et al. 2016; Puentes-Téllez and Salles 2018; Ventorino et al. 2015). In particular, the genus Microbacterium together with Bacillales such as Paenibacillus or Bacillus have demonstrated to be the key bacteria of synthetic lignocellulose-degrading minimal consortia (Jiménez et al. 2018; Azizi et al. 2018). Metagenomic data would allow to predict the roles of microbial species in degradation; however, the ecological relationships define the specific participation of each member. Thus, a metatranscriptomic and secretomic analysis are necessary to unveil the enzyme producers along degradation.

The microbial population of PM-06 presented a cyclical behaviour with the existence of a minimum set of bacterial species possibly conformed by the Aneurinibacillus, Bacillus, Paenibacillus, and Microbacterium genera, whose presence and ecological relationships would be important to preserve the consortium viability and degradation capacity (De Lima Brossi et al. 2016; Lee et al. 2013; Puentes-Téllez and Salles 2018).

Consortium PM-06 is an efficient NMP degrader and a prolific endo-xylanase producer. The mechanism utilized for NMP degradation was sequential where the substrate structure, microbial growth, $\mathrm{pH}$, synergistic relation between enzymes, ecological relationships, and microbial dynamics were intimate related. All the tools generated by the consortium worked coordinated to increase the substrate availability through the solubilization of components and elimination of structural diffusion barriers. More studies are necessary to analyze the whole set of enzymes produced, the effect of $\mathrm{pH}$ on the enzyme activity and stability, gene regulation strategies, and changes in NMP permeation along time, to obtain specific information of the mechanism. This is the first report about the degradation of NMP using a microbial consortium.

\section{Additional file}

Additional file 1: Table S1. Metrics of assembled metagenome. Figure S1. SEM Micrograph of nixtamalized maize pericarp surface morphology after sterilization by autoclaving at $121^{\circ} \mathrm{C}$ for $15 \mathrm{~min}$.

\section{Abbreviations}

CMC: carboxymethylcellulose; DGGE: denaturant gradient gel electrophoresis; DNS: 3,5-dinitrosalicylic acid; DP: degree of polymerization; NMP: nixtamalized maize pericarp; SEM: scanning electron microscopy; OTUs: operative taxonomic units.

\section{Acknowledgements}

The authors thank Harinera de Yucatán, SA de CV for providing the nixtamalized maize pericarp. In addition, authors thank Dr. Pedro J Cabello Yeves for the support in the bioinformatic analysis and QFB Karla Kú Durán and IB Erik IC for the technical assistance.

\section{Authors' contributions}

JGSG performed experiments; MNSG, RARH and JGSG participated in the design of experiments and interpretation of data; AGB and JGSG designed and performed bacterial community dynamics experiments; JLFM and DJJ participated in the critical revision of manuscript; DJJ and MNSG participated in the analysis and discussion of data; JGSG wrote the manuscript with support from DJJ and MNSG; MNSG conceived the original idea. All authors read and approved the final manuscript.

\section{Funding}

This research was supported by CONACyT project CB 242952. JGSG received a CONACyT doctoral fellowship.

\section{Availability of data and materials}

The metagenome analyzed in this article is available in NCBI portal with the Bio Project ID PRJNA522744 (Biosample accession: SAMN10953775).

\section{Ethics approval and consent to participate}

This article does not contain any studies with human participants or animals performed by any of the authors.

\section{Consent for publication}

This article does not contain any individual person's data.

\section{Competing interests}

The authors declare that they have no competing interests.

\section{Author details}

${ }^{1}$ Facultad de Ingeniería Química, Universidad Autónoma de Yucatán, Campus Ciencias Exactas e Ingenierías, Periférico Norte, Kilómetro 33.5, Tablaje Catastral 13615, Chuburná de Hidalgo Inn, Mérida, Yucatán, Mexico. ${ }^{2}$ Centro de Investigación en Biotecnología, Universidad Autónoma del Estado de Morelos, Cuernavaca, Mexico. ${ }^{3}$ Microbiomes and Bioenergy Research Group, Department of Biological Sciences, Universidad de los Andes, Bogotá, Colombia.

Received: 13 March 2019 Accepted: 8 June 2019

Published online: 13 June 2019

\section{References}

Agger J, Viksø-Nielsen A, Meyer AS (2010) Enzymatic xylose release from pretreated corn bran arabinoxylan: differential effects of deacetylation and deferuloylation on insoluble and soluble substrate fractions. J Agric Food Chem 58:6141-6148. https://doi.org/10.1021/jf100633f

Alessi AM, Bird SM, Oates NC, LiY, Dowle AA, Novotny EH, deAzevedo ER, Bennett JP, Polikarpov I, Young JPW, McQueen-Mason SJ, Bruce NC (2018) Defining functional diversity for lignocellulose degradation in a microbial community using multi-omics studies. Biotechnol Biofuels 11:166. https //doi.org/10.1186/s13068-018-1164-2

Asem D, Leo W, Passari AK, Tonsing MV, Joshi JB, Uthandi S, Hashem A, Abd_ Allah EF, Singh BP (2017) Evaluation of gastrointestinal bacterial population for the production of holocellulose enzymes for biomass deconstruction. PLoS ONE 12:10. https://doi.org/10.1371/journal.pone.0186355

Auer L, Lazuka A, Sillam-Dussès D, Miambi E, O’Donohue M, HernandezRaquet G (2017) Uncovering the potential of termite gut microbiome for lignocellulose bioconversion in anaerobic batch bioreactors. Front Microbiol 8:2623. https://doi.org/10.3389/fmicb.2017.02623

Azizi A, Maia MRG, Fonseca AJM, Sharifi A, Fazaeli H, Cabrita ARJ (2018) Rumen fermentation of lignocellulosic biomass from wheat straw and date leaf inoculated with bacteria isolated from termite gut. J Anim Feed Sci 27:211-218. https://doi.org/10.22358/jafs/92423/2018 
Azizi-Shotorkhoft A, Mohammadabadi T, Motamedi H, Chaji M, Fazaeli H (2016) Isolation and identification of termite gut symbiotic bacteria with lignocellulose-degrading potential, and their effects on the nutritive value for ruminants of some by-products. Anim Feed Sci Technol 221:234-242. https://doi.org/10.1016/j.anifeedsci.2016.04.016

Bhatia L, Johri S, Ahmad R (2012) An economic and ecological perspective of ethanol production from renewable agro waste: a review. AMB Express 2:65. https://doi.org/10.1186/2191-0855-2-65

Biely P, Singh S, Puchart V (2016) Towards enzymatic breakdown of complex plant xylan structures: state of the art. Biotechnol Adv 34:1260-1274. https://doi.org/10.1016/j.biotechadv.2016.09.001

Bissaro B, Varnai A, Røhr ÅK, Eijsink VG (2018) Oxidoreductases and reactive oxygen species in conversion of lignocellulosic biomass. Microbiol Mol Biol Rev 82:e00029-18. https://doi.org/10.1128/MMBR.00029-18

Bohacz J (2018) Microbial strategies and biochemical activity during lignocellulosic waste composting in relation to the occurring biothermal phases. J Environ Manag 206:1052-1062. https://doi.org/10.1016/j.jenvm an.2017.11.077

Bolger AM, Lohse M, Usadel B (2014) Trimmomatic: a flexible trimmer for Illumina sequence data. Bioinformatics 30:2114-2120. https://doi. org/10.1093/bioinformatics/btu170

Buchfink B, Xie C, Huson DH (2014) Fast and sensitive protein alignment using DIAMOND. Nat Methods 12:59. https://doi.org/10.1038/nmeth.3176

Campechano-Carrera EM, Figueroa-Cárdenas JdeD, Arámbula-Villa G, Martínez Flores HE, Jiménez Sandoval SJ, Luna Bárcenas JG (2012) New ecological nixtamalisation process for tortilla production and its impact on the chemical properties of whole maize flour and wastewater effluents. Int J Food Sci Technol 47:564-571. https://doi.org/10.111 $1 / j .1365-2621.2011 .02878 . x$

Carlos C, Fan H, Currie CR (2018) Substrate shift reveals roles for members of bacterial consortia in degradation of plant cell wall polymers. Front Microbiol 9:364. https://doi.org/10.3389/fmicb.2018.00364

Carvajal-Millan E, Rascón-Chu A, Márquez-Escalante JA, Micard V, de León NP, Gardea A (2007) Maize bran gum: extraction, characterization and functional properties. Carbohydr Polym 69:280-285. https://doi.org/10.1016/j. carbpol.2006.10.006

Ciolacu DE (2018) Biochemical modification of lignocellulosic biomass. In: Popa V, Volf I (eds) Biomass as renewable raw material to obtain bioproducts of high-tech value. Elsevier, Amsterdam, pp 315-350. https://doi. org/10.1016/C2015-0-05810-5

Correia MA, Mazumder K, Brás JL, Firbank SJ, Zhu Y, Lewis RJ, York WS, Fontes CM, Gilbert HJ (2011) Structure and function of an arabinoxylan-specific xylanase. J Biol Chem 286:22510-22520. https://doi.org/10.1074/jbc. M110.217315

Cortes-Tolalpa L, Jiménez DJ, De Lima Brossi MJ, Salles JF, van Elsas JD (2016) Different inocula produce distinctive microbial consortia with similar lignocellulose degradation capacity. Appl Microbiol Biotechnol 100:77137725. https://doi.org/10.1007/s00253-016-7516-6

De Lima Brossi MJ, Jiménez DJ, Cortes-Tolalpa L, van Elsas JD (2016) Soilderived microbial consortia enriched with different plant biomass reveal distinct players acting in lignocellulose degradation. Microb Ecol 71:616-627. https://doi.org/10.1007/s00248-015-0683-7

Decimo M, Quattrini M, Ricci G, Fortina MG, Brasca M, Silvetti T, Manini F, Erba D, Criscuoli F, Casiraghi MC (2017) Evaluation of microbial consortia and chemical changes in spontaneous maize bran fermentation. AMB Express 7:205. https://doi.org/10.1186/s13568-017-0506-y

Du R, Yan J, Li S, Zhang L, Zhang S, Li J, Zhao G, Qi P (2015) Cellulosic ethanol production by natural bacterial consortia is enhanced by Pseudoxanthomonas taiwanensis. Biotechnol Biofuels 8:10. https://doi.org/10.1186/ s13068-014-0186-7

DuBois M, Gilles KA, Hamilton JK, Rebers PT, Smith F (1956) Colorimetric method for determination of sugars and related substances. Anal Chem 28:350-356. https://doi.org/10.1021/ac60111a017

Evans R, Alessi AM, Bird S, McQueen-Mason SJ, Bruce NC, Brockhurst MA (2017) Defining the functional traits that drive bacterial decomposer community productivity. ISME J 11:1680. https://doi.org/10.1038/ismej.2017.22

Evstigneev El (2011) Factors affecting lignin solubility. Russ J Appl Chem 84:1040-1045. https://doi.org/10.1134/S1070427211060243

Fierer N, Nemergut D, Knight R, Craine JM (2010) Changes through time: integrating microorganisms into the study of succession. Res Microbiol 161:635-642. https://doi.org/10.1016/j.resmic.2010.06.002
Future Market Insights (2018) Tortilla market: unique recipes incorporating different types of tortilla to foster revenue growth: global industry analysis \& opportunity assessment. https://www.futuremarketinsights .com/reports/tortilla-market. Accessed 25 Feb 2019

Gao J, Zhao Y, Zhang G, Li Y, Li Q (2018) Production optimization, purification, expression, and characterization of a novel $a-L_{-}$ arabinofuranosidase from Paenibacillus polymyxa. Electron J Biotechnol 36:24-33. https://doi.org/10.1016/j.ejbt.2018.09.002

García-Zamora JL, Sánchez-González M, Lozano JA, Jáuregui J, Zayas T, Santacruz V, Hernández F, Torres E (2015) Enzymatic treatment of wastewater from the maize tortilla industry using chitosan as an adsorbent reduces the chemical oxygen demand and ferulic acid content. Process Biochem 50:125-133. https://doi.org/10.1016/j.procb io.2014.10.012

Gastelum-Arellanez A, Paredes-López O, Olalde-Portugal V (2014) Extracellular endoglucanase activity from Paenibacillus polymyxa BEb-40: production, optimization and enzymatic characterization. World J Microbiol Biotechnol 30:2953-2965

Ghio S, Ontañon O, Piccinni FE, de Villegas RMD, Talia P, Grasso DH, Campos E (2018) Paenibacillus sp. A59 GH10 and GH11 extracellular endoxylanases: application in biomass bioconversion. Bioenergy Res 11:174190. https://doi.org/10.1007/s12155-017-9887-7

Gutierrez E, Rojas-molina I, Pons-Hernandez JL, Guzman H, Augus-Angel B, Arenas J, Fernandez P, Palacios-Fonseca A, Herrena G, Rodríguez ME (2007) Study of calcium ion diffusion in nixtamalized quality protein maize as a function of cooking temperature. Cereal Chem 84:186-194. https://doi.org/10.1094/CCHEM-84-2-0186

Gutiérrez-Cortez E, Rojas-Molina I, Rojas A, Arjona JL, Cornejo-Villegas MA, Zepeda-Benítez Y, Velázquez-Hernández R, Ibarra-Alvarado C, Rodríguez-García ME (2010) Microstructural changes in the maize kernel pericarp during cooking stage in nixtamalization process. J Cereal Sci 51:81-88. https://doi.org/10.1016/j.jcs.2009.09.008

Gutiérrez-Cortez E, Rojas-Molina I, Zambrano-Zaragoza ML, EspinosaArbelaez D, Rojas A, García JC, Cornejo-Villegas MA, Rodríguez-García ME (2016) The mass transport phenomenon through pericarp during the nixtamalization process. Food Bioprod Process 100:477-486. https ://doi.org/10.1016/j.fbp.2016.09.008

Hu J, Arantes V, Saddler JN (2011) The enhancement of enzymatic hydrolysis of lignocellulosic substrates by the addition of accessory enzymes such as xylanase: is it an additive or synergistic effect? Biotechnol Biofuels 4:36. https://doi.org/10.1186/1754-6834-4-36

Hu J, Tian D, Renneckar S, Saddler JN (2018) Enzyme mediated nanofibrillation of cellulose by the synergistic actions of an endoglucanase, lytic polysaccharide monooxygenase (LPMO) and xylanase. Sci Rep 8:3195. https://doi.org/10.1038/s41598-018-21016-6

Hui W, Jiajia L, Yucai L, Peng G, Xiaofen W, Kazuhiro M, Zongjun C (2013) Bioconversion of un-pretreated lignocellulosic materials by a microbial consortium XDC-2. Bioresour Technol 136:481-487. https://doi. org/10.1016/j.biortech.2013.03.015

Jiménez DJ, Dini-Andreote F, DeAngelis KM, Singer SW, Salles JF, van Elsas JD (2017) Ecological insights into the dynamics of plant biomassdegrading microbial consortia. Trends Microbiol 25:788-796. https:// doi.org/10.1016/j.tim.2017.05.012

Jiménez DJ, Chaib De Mares M, Salles JF (2018) Temporal expression dynamics of plant biomass-degrading enzymes by a synthetic bacterial consortium growing on sugarcane bagasse. Front Microbiol 9:299. https:// doi.org/10.3389/fmicb.2018.00299

Jose VL, Appoothy T, More RP, Arun AS (2017) Metagenomic insights into the rumen microbial fibrolytic enzymes in Indian crossbred cattle fed finger millet straw. AMB Express 7:13. https://doi.org/10.1186/s1356 8-016-0310-0

Keggi C, Doran-Peterson J (2019) Paenibacillus amylolyticus 27C64 has a diverse set of carbohydrate-active enzymes and complete pectin deconstruction system. J Ind Microbiol Biotechnol 46:1-11. https://doi. org/10.1007/s10295-018-2098-1

Kim IJ, Lee HJ, Choi IG, Kim KH (2014) Synergistic proteins for the enhanced enzymatic hydrolysis of cellulose by cellulase. Appl Microbiol Biotechnol 98:8469-8480. https://doi.org/10.1007/s00253-014-6001-3

Kurrataa'Yun Y, Meryandini A (2015) Characterization of xylanase activity produced by Paenibacillus sp. XJ18 from TNBD Jambi, Indonesia. HAYATI J Biosci 22:20-26. https://doi.org/10.4308/hjb.22.1.20 
Lee DJ, Show KY, Wang A (2013) Unconventional approaches to isolation and enrichment of functional microbial consortium - a review. Bioresour Technol 136:697-706. https://doi.org/10.1016/j.biortech.2013.02.075

Li S, Shao N, Luo Y, Liu H, Cai S, Dong X (2017) Transcriptome and zymogram analyses reveal a cellobiose-dose related reciprocal regulatory effect on cellulase synthesis in Cellulosilyticum ruminicola H1. Front Microbiol 8:2497. https://doi.org/10.3389/fmicb.2017.02497

Liang J, Lin Y, LiT, Mo F (2017) Microbial consortium OEM1 cultivation for higher lignocellulose degradation and chlorophenol removal. RSC Adv 7:39011-39017. https://doi.org/10.1039/C7RA04703G

López-Martinez LX, Parkin KL, Garcia HS (2011) Phase II-inducing, polyphenols content and antioxidant capacity of maize (Zea mays L.) from phenotypes of white, blue, red and purple colors processed into masa and tortillas. Plant Foods Hum Nutr 66:41-47. https://doi.org/10.1007/s1113 $0-011-0210-z$

Malgas S, Thoresen M, van Dyk JS, Pletschke BI (2017) Time dependence of enzyme synergism during the degradation of model and natural lignocellulosic substrates. Enzyme Microb Technol 103:1-11. https://doi. org/10.1016/j.enzmictec.2017.04.007

Miller GL (1959) Use of dinitrosalicylic acid reagent for determination of reducing sugar. Anal Chem 31:426-428. https://doi.org/10.1021/ac60147a030

Mongkorntanyatip K, Limsakul P, Ratanakhanokchai K, Khunrae P (2017) Overexpression and characterization of alkaliphilic Bacillus firmus strain K-1 xylanase. Agric Nat Resour 51:437-444. https://doi.org/10.1016/j.anres .2018.03.011

Muyzer G, de Waal EC, Uitterlinden AG (1993) Profiling of complex microbial populations by denaturing gradient gel electrophoresis analysis of polymerase chain reaction-amplified genes encoding for 165 rRNA. Appl Environ Microbiol 59:695-700

Orencio-Trejo M, De la Torre-Zavala S, Rodriguez-Garcia A, Avilés-Arnaut H, Gastelum-Arellanez A (2016) Assessing the performance of bacterial cellulases: the use of Bacillus and Paenibacillus strains as enzyme sources for lignocellulose saccharification. Bioenergy Res 9:1023. https://doi. org/10.1007/s12155-016-9797-0

Papadimitriou K, Alegría Á, Bron PA, De Angelis M, Gobbetti M, Kleerebezem M, Lemos JA, Linares DM, Ross P, Stanton C, Turroni F, van Sinderen D, Varmanen P, Ventura M, Zúñiga M, Tsakalidou E, Kok J (2016) Stress physiology of lactic acid bacteria. Microbiol Mol Biol Rev 80:837-890. https:// doi.org/10.1128/MMBR.00076-15

Peng Y, Leung HC, Yiu SM, Chin FY (2012) IDBA-UD: a de novo assembler for single-cell and metagenomic sequencing data with highly uneven depth. Bioinformatics 28:1420-1428. https://doi.org/10.1093/bioinforma tics/bts 174

Peterson GL (1977) A simplification of the protein assay method of Lowry which is more generally applicable. Anal Biochem 83:346-356. https:// doi.org/10.1016/0003-2697(77)90043-4

Pometto AL, Crawford DL (1986) Effects of pH on lignin and cellulose degradation by Streptomyces viridosporus. Appl Environ Microbiol 52:246-250

Puentes-Téllez PE, Salles JF (2018) Construction of effective minimal active microbial consortia for lignocellulose degradation. Microb Ecol 76:419. https://doi.org/10.1007/s00248-017-1141-5

Ravi K, García-Hidalgo J, Gorwa-Grauslund MF, Lidén G (2017) Conversion of lignin model compounds by Pseudomonas putida KT2440 and isolates from compost. Appl Microbiol Biotechnol 101:5059-5070. https://doi. org/10.1007/s00253-017-8211-y

Rojas-Herrera R, Narváez-Zapata J, Zamudio-Maya M, Mena-Martínez ME (2008) A simple silica-based method for metagenomic DNA extraction from soil and sediments. Mol Biotechnol 40:13-17. https://doi. org/10.1007/s12033-008-9061-8

Rostro-Alanís M, Sánchez-González M, Rivas S, Moure A, Domínguez H, Parajó JC (2014) Non-isothermal autohydrolysis of nixtamalized maize pericarp: production of nutraceutical extracts. LWT-Food Sci Technol 58:550-556. https://doi.org/10.1016/j.lwt.2014.03.043

Sadhu S, Maiti TK (2013) Cellulase production by bacteria: a review. Br Microbiol Res J 3:235. https://doi.org/10.9734/BMRJ/2013/2367

Salmeron-Alcocer A, Rodriguez-Mendoza N, Pineda-Santiago S, CristianiUrbina E, Juarez-Ramirez C, Ruiz-Ordaz N, Galindez-Mayer J (2003) Aerobic treatment of maize processing wastewater (nejayote) in a single stream multi stage reactor. J Environ Eng Sci 2:401-406. https://doi. org/10.1139/s03-046

Sanchez-Gonzalez M, Blanco-Gamez A, Escalante A, Valladares AG, Olvera C, Parra R (2011) Isolation and characterization of new facultative alkaliphilic Bacillus flexus strains from maize processing waste water (nejayote). Lett Appl Microbiol 52:413-419. https://doi.org/10.1111/j.1472765X.2011.03021.X

Serna-Saldivar JO (2016) History of corn and wheat tortillas. In: Rooney LW, Serna-Saldivar JO (eds) Tortillas: wheat flour and corn products. AACC International Inc., St. Paul

Tláskal V, Zrůstová P, Vrška T, Baldrian P (2017) Bacteria associated with decomposing dead wood in a natural temperate forest. FEMS Microbiol Ecol 93:12. https://doi.org/10.1093/femsec/fix157

Ventorino V, Aliberti A, Faraco V, Robertiello A, Giacobbe S, Ercolini D, Amore A, Fagnano M, Pepe O (2015) Exploring the microbiota dynamics related to vegetable biomasses degradation and study of lignocellulose-degrading bacteria for industrial biotechnological application. Sci Rep 5:8161-8174. https://doi.org/10.1038/srep08161

Wongwilaiwalin S, Rattanachomsri U, Laothanachareon T, Eurwilaichitr L, Igarashi Y, Champreda V (2010) Analysis of a thermophilic lignocellulose degrading microbial consortium and multi-species lignocellulolytic enzyme system. Enzyme Microb Technol 47:283-290. https://doi. org/10.1016/j.enzmictec.2010.07.013

Yeager CM, Dunbar J, Hesse CN, Daligault H, Kuske CR (2017) Polysaccharide degradation capability of Actinomycetales soil isolates from a semi-arid grassland of the Colorado Plateau. App Environ Microb 83:6. https://doi. org/10.1128/AEM.03020-16

Zhang B, Liu Y, Yang H, Yan Q, Yang S, Jiang ZQ, Li S (2017) Biochemical properties and application of a novel $\beta-1,3-1,4$-glucanase from Paenibacillus barengoltzii. Food Chem 234:68-75. https://doi.org/10.1016/j.foodc hem.2017.04.162

Zhang D, Wang Y, Zhang C, Zheng D, Guo P, Cui Z (2018) Characterization of a thermophilic lignocellulose-degrading microbial consortium with high extracellular xylanase activity. J Microbiol Biotechnol 28:305-313. https:// doi.org/10.4014/jmb.1709.09036

Zhu N, Yang J, Ji L, Liu J, Yang Y, Yuan H (2016) Metagenomic and metaproteomic analyses of a maize stover-adapted microbial consortium EMSD5 reveal its taxonomic and enzymatic basis for degrading lignocellulose. Biotechnol Biofuels 9:243. https://doi.org/10.1186/s13068-016-0658-z

\section{Publisher's Note}

Springer Nature remains neutral with regard to jurisdictional claims in published maps and institutional affiliations. 